\title{
Insight Into the Leaching of Sodium Alumino-Silicate Hydrate (N-A-S-H) Gel: A Molecular Dynamics Study
}

\author{
Hongyan Wan ${ }^{1}$, Liqun Yuan ${ }^{2}$ and Yu Zhang ${ }^{1 *}$ \\ ${ }^{1}$ School of Materials Science and Engineering, Southeast University, Naniing, China, ${ }^{2}$ School of Architecture and Civil \\ Engineering, Liaocheng University, Liaocheng, China
}

This paper provides an intrinsic mechanism for alkali dissolution from the gels of geopolymers at the nanoscale, via a molecular dynamics (MD) investigation on N-A-S-H gel, the predominant binding phase in geopolymers. Sodium plays roles in balancing the charges of $\left[\mathrm{AlO}_{4}\right]$ tetrahedrons, and its absence causes local structures to show a negative charge, resulting in locally mutual repulsion between tetrahedrons. Also, sodium dissociation promotes a hydrolytic reaction, exacerbating the non-conservation of charge of the N-A-S-H system, further swelling the structure. The above evolution weakens the alumino-silicate skeleton and reduces the stability of silicate and aluminate species, which in turn promotes sodium dissociation. In the long term, it increases

OPEN ACCESS

Edited by:

Dongshuai Hou,

Qingdao University of

Technology, China

Reviewed by:

Zuhua Zhang,

Hunan University, China

Jianguo $L i$

Bioinformatics Institute

(A*STAR), Singapore

*Correspondence:

Yu Zhang

tgyuzhang@outlook.com

Specialty section:

This article was submitted to Computational Materials Science,

a section of the journal

Frontiers in Materials

Received: 28 December 2019

Accepted: 21 February 2020

Published: 24 March 2020

Citation:

Wan H, Yuan L and Zhang Y (2020) Insight Into the Leaching of Sodium Alumino-Silicate Hydrate (N-A-S-H)

Gel: A Molecular Dynamics Study.

Front. Mater. 7:56.

doi: 10.3389/fmats.2020.00056 the potential of structure depolymerization and even peeling off. Based on previously reported experiments and our computational results, it is likely that leaching starts from the N-A-S-H substrate surface, and the gel peels off layer by layer in the above manner, resulting in microscopic holes and fissures. In addition, leaching also leads to the degradation of the mechanical properties of the surface gel, including Young's modulus, tensile strength, and ductility, which considerably increases the possibility of surface gel peeling. Additionally, sodium is able to connect $\left[\mathrm{AlO}_{4}\right]$ and $\left[\mathrm{SiO}_{4}\right]$ tetrahedrons by the electrostatic force with tetrahedral oxygen, which transfers stress and contributes to uniform stress dispersion.

Keywords: geopolymer, leaching, molecular dynamics, N-A-S-H gel, alkalis

\section{INTRODUCTION}

Sodium alumino-silicate hydrate (N-A-S-H) gel is the primary binding phase in geopolymers, and determines the durability and mechanical properties of these materials. With respect to the geopolymer, it is an alkali-activated material and is considered to be an alternative to conventional Portland cement (PC). Using industrial by-products as a precursor, developing geopolymers can reduce carbon oxide emissions and energy consumption as compared to PC materials (Habert et al., 2011; Singh et al., 2015). Importantly, it also shows mechanical properties comparable to PC and even much better durability (Shi et al., 2011; Provis et al., 2015; Arbi et al., 2016; Zhang et al., 2018d). The geopolymer can be prepared by mixing fly ash or metakaolin with an alkaline solution and curing at an elevated temperature (around $60 \sim 80^{\circ} \mathrm{C}$ ). Generally, the molecular structure of the reaction product is described as a three-dimensional alumino-silicate network constructed by $\left[\mathrm{SiO}_{4}\right]$ and $\left[\mathrm{AlO}_{4}\right]$ tetrahedrons interlinked by bridging oxygen, with alkali ions $\left(\mathrm{Na}^{+}\right.$or $\left.\mathrm{K}^{+}\right)$loosely bound to $\left[\mathrm{AlO}_{4}\right]$ tetrahedrons and compensating for the negative charge of four-coordinated aluminum 
(Duxson et al., 2005, 2007; Provis and Van Deventer, 2007). This reaction product is called sodium (or potassium) alumino-silicate hydrate $[\mathrm{N}(\mathrm{K})-\mathrm{A}-\mathrm{S}-\mathrm{H}]$ gel.

Leaching generally occurs with geopolymers, especially when exposed to flowing fresh water or weak acids, as these remove sodium from the geopolymer paste. Leaching begins with aqueous sodium in the pore solution, which can be seen as sodium transporting inside the pore structure of the geopolymer before being discharged from the material. Consequently the reduced sodium concentration in the pore solution results in solid sodium dissolving from the gel. These two processes promote each other. Leaching is closely associated with various types of material degradation. From a macro perspective, the results caused by leaching are typically a decrease in $\mathrm{pH}$ value in the pore solution (Zhang et al., 2013, 2014), a decline in the quality of geopolymer specimens (Zhang et al., 2016), coarsening of pore structure (Yao et al., 2016), and degradation of mechanical properties (e.g., compressive strength, tensile strength, and Young's modulus) (Yao et al., 2016; Zhang et al., 2016). The degradation can be explained by the weakening of $\mathrm{AlO}_{4}$ 's tetrahedral structure whose net negative charge is normally balanced by alkalis, which was characterized by both a molecular dynamics simulation (Sadat et al., 2016a) and ${ }^{29} \mathrm{Si}$ and ${ }^{27} \mathrm{Al}$ MAS-NMR and FTIR analysis (Longhi et al., 2019). It also matches well with the experimental results of the detection of aluminate species in water soaked geopolymer specimens (Zhang et al., 2016), which means the dealumination of the gel and thus dissolution of the gel.

The leaching can be divided into two processes which are the movement of aqueous alkalis in the pore solution and the extraction of alkalis from the gels. With respect to the former, previous works have shown that the transportation of free alkalis in the pore solution (resulting from excess, weakly-bonded or unreacted alkalis) is influenced by pore structure, where a looser and less tortuous pore network promotes movement of alkali cations (Lloyd et al., 2010; Zhang et al., 2018d). At present, a majority of the relevant published papers focus on the mix proportion of geopolymer materials and the curing environment used in order to reach denser pore structures and less free alkali in the materials. The aim of which is to create low leaching potentials, by methods, such as the selection of activators and the addition of supplementary cementitious materials (e.g., slag, metakaolin, and calcium aluminate cements) (Kani et al., 2012; Zhang et al., 2013, 2014; Yao et al., 2016; Longhi et al., 2020).

It is worth noting that leaching has a special manifestation that is efflorescence. It happens when geopolymer materials are in contact with damp soil at their base, from which water is drawn through the material by capillary action carrying alkalis with it which evaporate from the concrete surface, leaving the alkalis deposited on the surface where they react with atmospheric $\mathrm{CO}_{2}$, resulting in the formation of white carbonate deposits on the surface known as efflorescence. Obviously, the influencing factors for efflorescence are carbonization in addition to alkali transport. It seems that the deleterious effect of efflorescence on the geopolymer is greater than that of leaching only (Yao et al., 2016). Zhang et al. (2018d) reported subflorescence which is efflorescence taking place under the surface of a material, forming sodium carbonate crystallization pressure under the material surface, generating greater material damage.

The above-mentioned hazards can be attributed to the continued dissolution of sodium from the gel. Therefore, studies related to the extraction of alkalis from gels is necessary, including investigating the roles sodium plays in the gel and the reasons for sodium dissolution. Solid phase sodium may not be involved in alumino-silicate skeleton formation (Škvára et al., 2012). In the results of a ${ }^{23} \mathrm{Na}$ MAS NMR (Duxson et al., 2005), there was no evidence of resonances resulting from sodium associating with non-bridging oxygen, which suggests that the interaction between solid sodium and the oxygen in the skeleton is very weak, and at the very least is not an ionic bond. Therefore, the dissolution of solid sodium can be attributed to the relatively weak binding of alkalis in the structure (Bortnovsky et al., 2008; Škvára et al., 2008; Szklorzová and Bílek, 2008). Some have attempted to utilize potassium hydroxide instead of sodium hydroxide as the alkali activator, due to the stronger electrostatic interaction between potassium and the alumino-silicate skeleton (Duxson et al., 2006; Longhi et al., 2020). By means of molecular dynamics, the computation results conducted by Zhang et al. (2018a) indicate that it is impossible for sodium to escape from inside the dense alumino-silicate network, but only from several nanometer-thick surface layers, where the binding energy is much lower. Additionally, they also reported the stabilizing effect of hydroxyls on the sodium in the gel (Zhang et al., 2018b).

However, there is still an absence of knowledge about the process by which alkalis are extracted from gels. To our knowledge, there are very few papers on this dedicated topic. This is due to the fact that relevant research involves the atomic scale, so the results obtained from experiments alone are scarce and some of them are obtained through indirect inference. Molecular dynamics (MD) has the potential to give such explanations. With force field parameters derived from first-principle theory computation, $\mathrm{MD}$ is able to provide a quantitative intrinsic illustration on the structure, reactivity, dynamics, and energy of the system on the molecular level.

Leaching begins from the surface of the gel. This paper simulated the leaching of a surface N-A-S-H gel with a volume of $2 \times 2 \times 2 \mathrm{~nm}$ to reveal the effect of alkali dissociation on $\mathrm{N}-\mathrm{A}-\mathrm{S}-\mathrm{H}$ gels and to give the mechanisms of the process of alkali dissociation from the gel. By means of reactive molecular dynamics, a model lacking sodium was constructed and the relevant evolutions of structure, dynamics, and mechanical properties were investigated.

\section{METHODOLOGY}

\section{Model Construction}

The N-A-S-H model can be constructed by the following procedures. At the beginning silicon, aluminum, sodium, and oxygen atoms, according to the chemical composition shown in Table 1, were randomly assigned in the simulation box with a size of $20 \times 20 \times 20 \AA$, with each atom separated by at least $2.2 \AA$ A. A periodic boundary was imposed in all three directions. Verlet algorithms were utilized to calculate the atomic trajectory. The structure was subjected to an NVT ensemble 
TABLE 1 | Chemical composition of the N-A-S-H model.

\begin{tabular}{|c|c|c|c|c|c|c|}
\hline Si/Al & $\mathrm{SiO}_{2}$ (wt. \%) & $\begin{array}{c}\mathrm{Al}_{2} \mathrm{O}_{3} \\
\text { (wt. \%) }\end{array}$ & $\begin{array}{c}\mathrm{Na}_{2} \mathrm{O} \\
\text { (wt. \%) }\end{array}$ & $\begin{array}{c}\mathrm{H}_{2} \mathrm{O} \\
\text { (wt. \%) }\end{array}$ & Skeletal density $\left(\mathrm{g} / \mathrm{cm}^{3}\right)$ & Gel density $\left(\mathrm{g} / \mathrm{cm}^{3}\right)$ \\
\hline 2 & 55.32 & 24.16 & 14.64 & 6.78 & 2.56 & 2.71 \\
\hline
\end{tabular}

at $300 \mathrm{~K}$ for $50 \mathrm{ps}$ and a subsequent NPT ensemble where the temperature was raised up to $4,000 \mathrm{~K}$ and then cooled down to $300 \mathrm{~K}$ at a healing/cooling rate of $5 \mathrm{~K} / \mathrm{ps}$. Then, the structure was subjected to an NPT ensemble at $300 \mathrm{~K}$ and 0 atm for structural equilibrium. Pressure was applied on all directions (i.e., $\mathrm{x}, \mathrm{y}$, and $\mathrm{z}$ directions). Finally, the Grand Canonical Monte Carlo (GCMC) method (Bonnaud et al., 2012), performed on LAMMPS, was performed for 300 million steps to adsorb water molecules into the structure until saturation.

The obtained N-A-S-H model is shown in Figure 1. The structure of N-A-S-H consists of a three-dimensional aluminosilicate skeleton filled with sodium and water molecules. Silicon and aluminum species are predominantly tetrahedral as listed in Table 2, and the Q4 $\left(\left[\mathrm{SiO}_{4}\right]\right.$ or $\left[\mathrm{AlO}_{4}\right]$ tetrahedron with four tetrahedrons connected around it) percentage is $79 \%$. The structure of the N-A-S-H model obtained matches with published results of MAS-NMR (Duxson et al., 2005; Singh et al., 2005; Bernal et al., 2013). Furthermore, a similar N-A-S-H model obtained by the same modeling approach has been presented in previously published articles and attained ideal modeling results related to the transport, structure, dynamics and mechanical properties of N-A-S-H (Sadat et al., 2016b; Zhang et al., 2018a,b).

In order to simulate the effect of leaching on the N-A-S-H gel, sodium atoms were deleted randomly from the structure. For a gel with a volume of $2 \times 2 \times 2 \mathrm{~nm}$ containing just a few dozens of sodium atoms, complete dissolution is possible when it is exposed to flowing water or acid. Thus, the leaching ratio was set as 0,25 , 50,75 , and $100 \%$.

\section{Reactive Force Field and Simulation Procedure}

Reactive force field (ReaxFF) was applied in this simulation to model the chemical reactions and dynamics of sodium, aluminum, silicon, oxygen, and hydrogen species in the N-A-S$\mathrm{H}$ gel. ReaxFF utilizes a bond order scheme to simulate chemical reactions. The interaction is determined by instantaneous interatomic distance, which is updated continuously to model chemical reactions. ReaxFF consists of bonded potential, including bond stretching energy, bond bending energy, bond torsion energy, and non-bonded potentials, including van der Waals and Coulombic potential. The bonded interaction is determined by the bond orders, so that all partial energy contributions of bonded interaction can reduce to zero smoothly as the bond breaks. The calculation of Coulombic potential is derived from the classical Coulomb force formula. The cutoff distance for long-range interaction is set as $10 \AA$.

The parameters of these species as described by ReaxFF are directly available in Bai et al. (2012). In previously published papers, ReaxFF has been confirmed to be accurate when

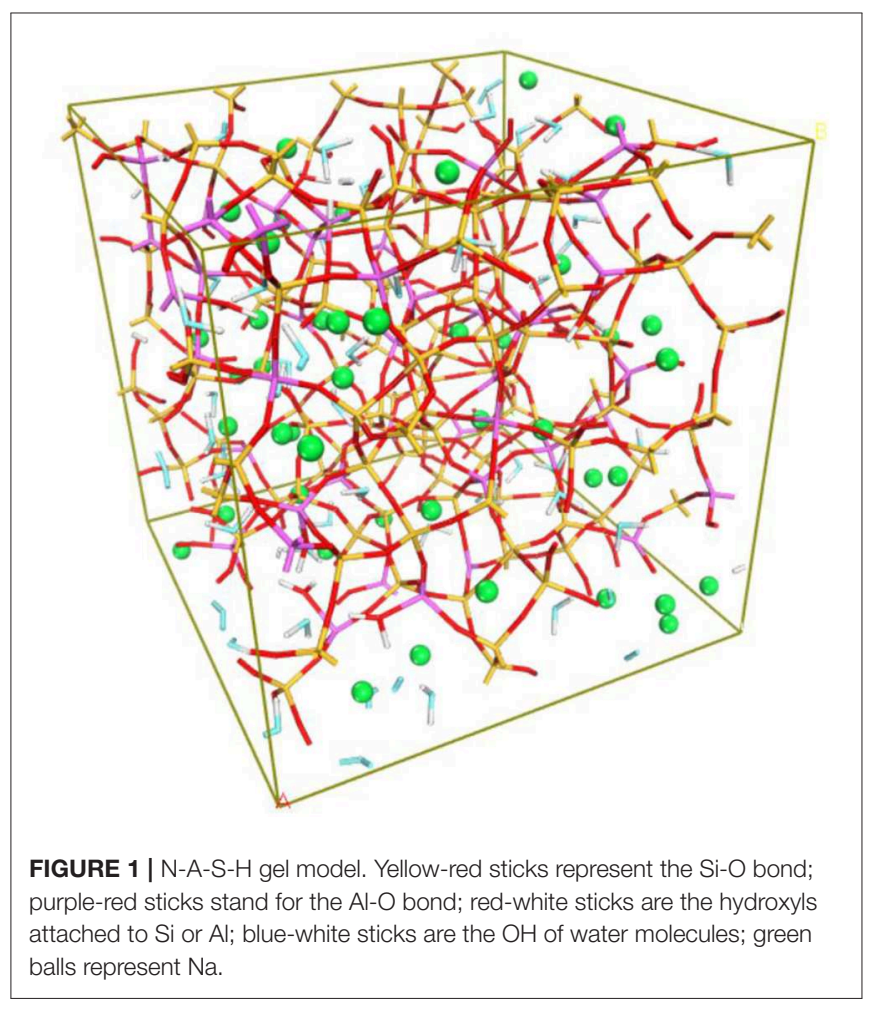

TABLE 2 | Coordination number (CN) of Al and Si in the N-A-S-H model.

\begin{tabular}{cccc}
\hline $\mathbf{C N}$ & $\mathbf{3}$ & $\mathbf{4}$ & $\mathbf{5}$ \\
\hline $\mathrm{Al}$ & $3.90 \%$ & $94.63 \%$ & $1.48 \%$ \\
$\mathrm{Si}$ & - & $100 \%$ & - \\
\hline
\end{tabular}

modeling glass and crystal systems with species of sodium, aluminum, silicon, such as silica glass (Hou et al., 2014), calcium silicate hydrate (Hou et al., 2019; Lu et al., 2020), calcium alumino-silicate hydrate (Wan et al., 2017; Hou et al., 2018a) and Tobermorite (Hou and Li, 2014), as well as N-A-S-H gels (Sadat et al., 2016b; Hou et al., 2018b, 2020; Zhang et al., 2018a,b, 2020) that are similar to the model in this paper.

The time step was 0.25 fs. Temperature and pressure were monitored and adjusted at regular intervals using the NoseHoover thermostat (Hoover, 1985) and Berendsen Barostat (Hoover, 1986) algorithms, respectively. The computational procedure was performed on LAMMPS, a molecular dynamics simulator. After leaching the N-A-S-H gel was relaxed on NPT and NVT ensembles for 100 ps. It turns out that structure equilibrium took only 40 ps. Then an NVT run of 100 ps was followed for structure analysis. Finally, a tensile test was 
conducted using a tensile strain rate of $0.08 / \mathrm{ps}$ under an NPT ensemble, which took 15 ps. As the model was elongated in the $\mathrm{x}$ direction, the pressure in the $\mathrm{y}$ and $\mathrm{z}$ directions was set as zero to reflect the Poisson effect. One frame of atomic trajectory was outputted every 1,000 steps for the analysis of structure and mechanical properties. The modeling of each leaching ratio was repeated three times, and the results were the same. The small amount of error is one of the advantages of simulation over experiments.

\section{RESULTS AND DISCUSSIONS}

\section{Structure Expansion of Surface Gel}

Leaching leads to an expansion of the N-A-S-H structure. As plotted in Figure 2, the simulation box size shows an exponential increase as the leaching ratio increases, and the volume increases from around 7,916.28 to 8,257.27 $\AA^{2}$ from the beginning to the complete dissociation of sodium. Generally, the leaching process is started from the exposed surface of N-A-S-H gel, because there are fewer electrostatic and geometric restrictions on sodium from the alumino-silicate skeleton (Zhang et al., 2018a). Under the influence of leaching, the gel of the surface swells, causing mismatches with internal deformation and generating internal stress, leading to a potential for cracking and peeling. The gel system has a considerably large specific surface area, and impacts caused by linear expansion of only $2 \%$ cannot be underestimated.

Sodium is loosely bound to aluminate tetrahedrons and plays a role in maintaining the charge neutrality of aluminate tetrahedrons in the N-A-S-H structure (Duxson et al., 2005). An absence of sodium leads local structures to show a negative charge, which results in mutual repulsion between $\left[\mathrm{SiO}_{4}\right]$ or $\left[\mathrm{AlO}_{4}\right]$ tetrahedrons in those local locations and eventually causes swelling of the overall structure.

Radial distribution functions (RDF) were utilized to characterize the interatomic spatial correlation to reflect the evolution of local structure caused by leaching. The RDFs of $\mathrm{Si}-\mathrm{Al}$ and $\mathrm{Si}-\mathrm{Si}$ are shown in Figure 3. The first peak of the $\mathrm{RDF}$ profiles represents the $\mathrm{Si}-\mathrm{O}-\mathrm{Al}$ bond and $\mathrm{Si}-\mathrm{O}-\mathrm{Si}$ bond. In Figure 3A, under the influence of leaching, the distance between $\mathrm{Si}$ and $\mathrm{Al}$ in the $\mathrm{Si}-\mathrm{O}-\mathrm{Al}$ bond increases from 3.12 to $3.27 \AA$, which is attributed to an increase in the $\mathrm{Si-O}-\mathrm{Al}$ angle caused by the repulsion between $\left[\mathrm{SiO}_{4}\right]$ and $\left[\mathrm{AlO}_{4}\right]$ tetrahedrons. It explains the observation from the FTIR spectra (Zhang et al., 2016) that the asymmetric stretching vibration band of Si-O-Al was shifted to a higher wavenumber after the leaching of the geopolymer sample. Essentially, this is due to the imbalance of charge caused by the lack of sodium, and confirms the conclusion that the important role of sodium is in maintaining the charge neutrality of aluminate tetrahedrons. The stretching of the alumino-silicate skeleton is one of the explanations for structure expansion. However, such a local structure evolution does not occur for the Si-O-Si bond. It seems that leaching may not influence the silicate skeleton directly.

ReaxFF utilizes a bond order scheme to determine the variation of interatomic interactions to accurately simulate chemical reactions. During the relaxation, a hydrolysis reaction can be observed as shown in Figure 4A. The oxygen species

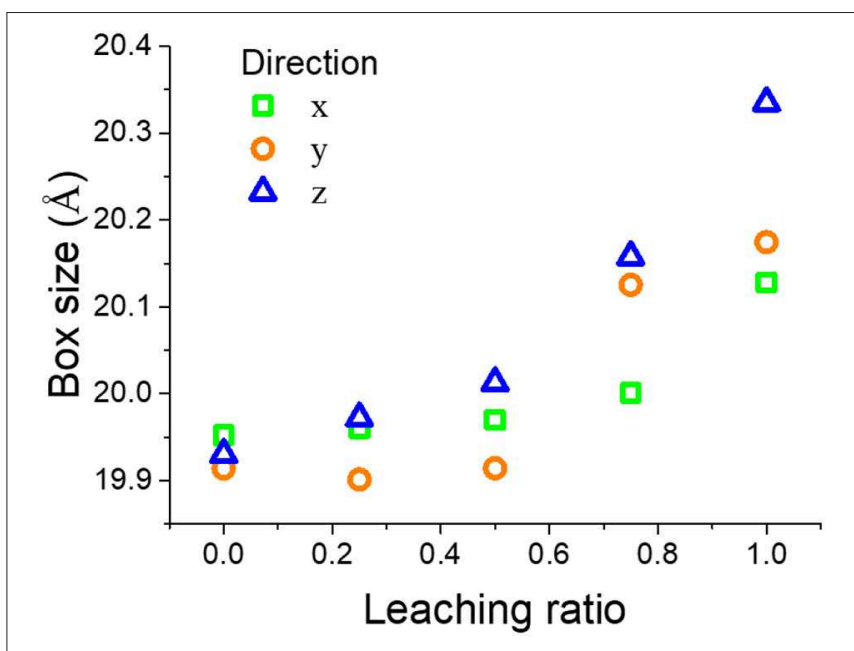

FIGURE 2 | Variation of N-A-S-H gel size with leaching ratio.

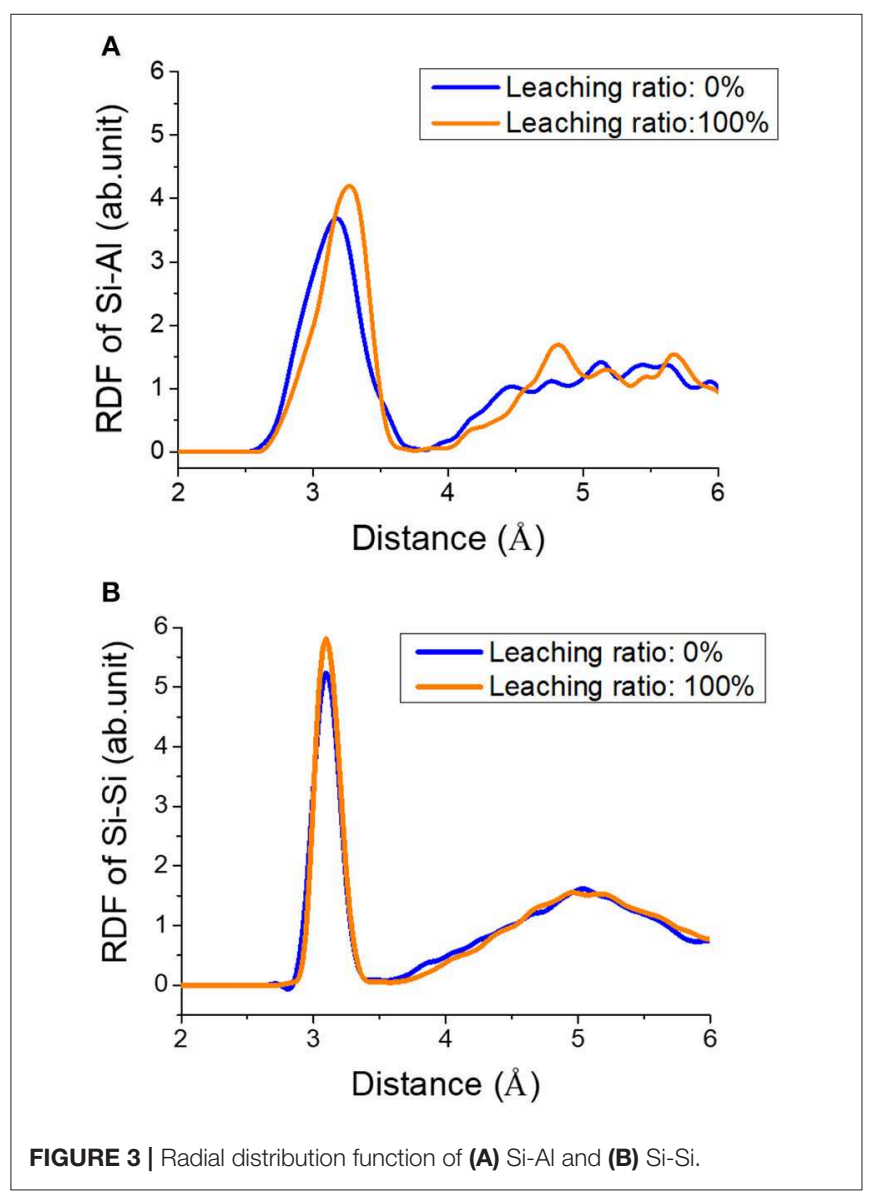

in the alumino-silicate skeleton attracts hydrogen atoms from nearby water molecules and occupies their electron, resulting in a hydrolytic reaction and the formation of $\mathrm{Si} / \mathrm{Al}-\mathrm{OH}$ and free $\mathrm{OH}^{-}$. This is because the sodium distributed among the aluminosilicate skeleton interacts with the oxygen species in the structure, such as non-bridging oxygen, and shares their charge. But the 

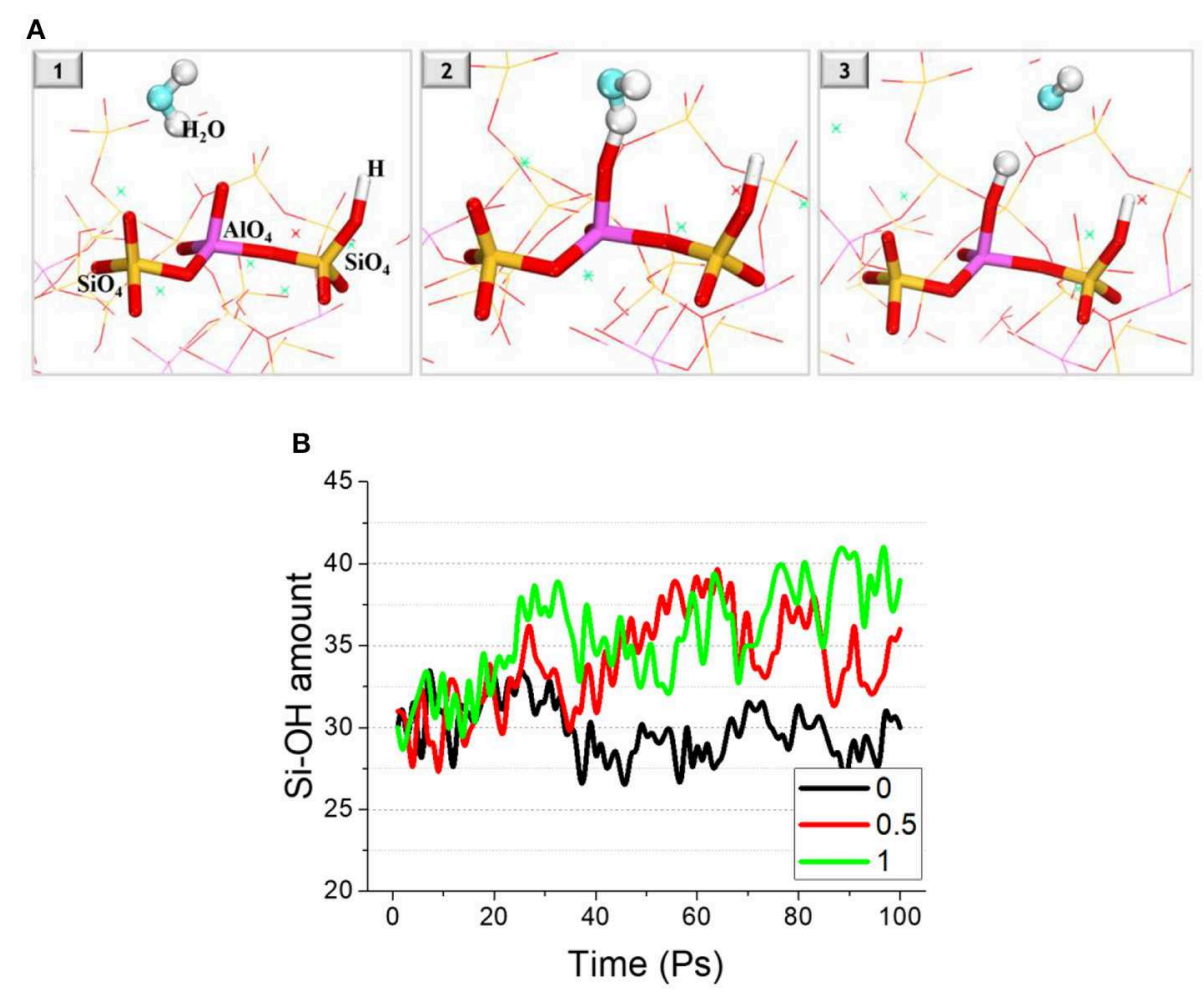

C

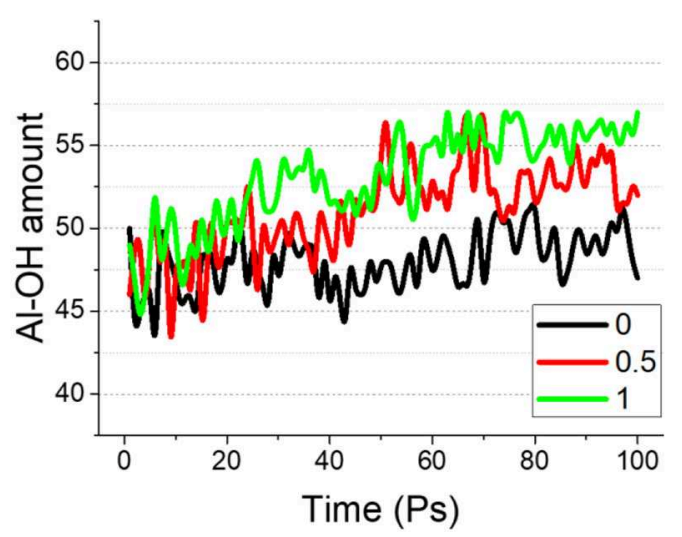

FIGURE 4 | (A) Snapshot of the hydrolysis reaction process, in which yellow-red sticks represent the Si-O bond; purple-red sticks stands for the Al-O bond; red-white sticks are the hydroxyls attached to Si or Al. The amount of (B) Si-O and (C) Al-O bonds as a function of time.

absence of sodium caused by leaching makes the originally stable oxygen species active again.

Figure 4 shows the variation in the amount of hydroxyls attached to the alumino-silicate skeleton ( $\mathrm{Si}-\mathrm{OH}$ and $\mathrm{Al}-\mathrm{OH}$ ), with or without the influence of leaching. For the reference sample (no leaching), the hydroxyl amount fluctuates but remains almost unchanged. By contrast, the amount of $\mathrm{Si}-\mathrm{OH}$ and $\mathrm{Al}-\mathrm{OH}$ increases with relaxation time for the samples with leaching. At $100 \mathrm{ps}$, the amount of $\mathrm{Si}-\mathrm{OH}$ and $\mathrm{Al}-\mathrm{OH}$ in the sample after $100 \%$ leaching has increased by around 8 times, and the increased amount for the sample after 50\% leaching is around 4 and 5 times.
It should be noted that the formation of hydroxyls in the N-A-S-H structure produced by the hydrolytic reaction mentioned above further swells the N-A-S-H structure. This is because that newly formed negatively-charged hydroxyls increase the level of non-conservation of charge for the $\mathrm{N}$ A-S-H system. However, due to the tendency toward charge neutral, a part of the hydrolytic reaction proceeds in the reverse direction, which gives a reason for the large fluctuation in the amount of hydroxyls in the structure over time. Ultimately, there are still some hydroxyls formed in the structure, which exacerbates the volume expansion of the N-AS-H gel. 
Furthermore, it has been reported (Zhang et al., 2018b) that hydrolytic reactions can also directly weaken the N-A-S-H structure. The stability of Al-O bonds is significantly reduced by the chemical reaction between water and aluminate tetrahedrons. But the stability of sodium is slightly improved, as a result of the restriction of newly formed $\mathrm{OH}^{-}$.

\section{Alumino-Silicate Skeleton Weakening}

Leaching not only swells the N-A-S-H structure as mentioned above, but also weakens parts of the alumino-silicate skeleton, including the weakening of $\mathrm{Si}-\mathrm{O}$ and $\mathrm{Al}-\mathrm{O}$ bonds and reducing the degree of polymerization of the N-A-S-H gel. A timecorrelated function (TCF), as determined by Equation (1), was applied to the system to estimate the stability of $\mathrm{Si}-\mathrm{O}$ and $\mathrm{Al}$ $\mathrm{O}$ bonds by counting the number of related bonds broken as functions of relaxation time.

$$
C(t)=\frac{<\delta b(t) \delta b(0)>}{<\delta b(0) \delta b(0)>}
$$

where $\delta b(t)$ is equal to $b(t)-\langle b\rangle$, and $\mathrm{b}(\mathrm{t})$ is a binary operator. If the chemical bond remains bonded, the value is one, otherwise it is zero; $<b>$ is the average value of $b$ during the whole simulation process.

The TCF profiles of Al-O and Si-O bonds are depicted in Figure 5. As simulation time goes, the TCF value begins to decay from 1 , which indicates the breaking of chemical bonds. A reduced value of $<0.01$ after 90 ps for the scenario without leaching shows the extreme stability of $\mathrm{Al}-\mathrm{O}$ and $\mathrm{Si}-\mathrm{O}$ bonds. As the leaching ratio increases, the rate of decline increases and the reduced value reaches around 0.02 , indicating that the weakening of $\mathrm{Al}-\mathrm{O}$ and $\mathrm{Si}-\mathrm{O}$ bonds is caused by leaching.

Under the influence of leaching, when compared with Si$\mathrm{O}$ bonds, there is a steeper downward gradient in the TCF profiles of Al-O bonds, implying that Al-O bonds are weakened more seriously by leaching. Sodium plays roles in maintaining the charge balance of aluminate tetrahedrons, and its absence has a direct effect on it. However, for the silicate tetrahedrons, they are only indirectly affected by structural expansion and the hydrolytic reaction mentioned in section Structure Expansion of Surface Gel, thus the stability of Si-O bonds shows a relatively slight decline.

In this stable environment, leaching may have little effect on the stability of Si/Al-O bonds, because a reduced value of 0.02 for the TCF profile after $90 \mathrm{ps}$ is still very small. A decreased value up to 0.4 has also been obtained for the stable $\mathrm{H}$-bond in the cement system when studied via an MD method (Zhang et al., 2018c). However, the effect of leaching only becomes apparent once the environment deteriorates, such as after structure deformation caused by loading or temperature variation.

Polymerization of N-A-S-H gel is characterized by the connectivity factor $\mathrm{Q}_{\mathrm{n}}$. It varies with the leaching ratio as shown in Figure 6. For a pristine sample (no leaching), $\mathrm{Q}_{4}$ is predominant and accounts for $79 \%$ of the sample, and is followed by $\mathrm{Q}_{3}$ at $19 \%$, and also there is a little $\mathrm{Q}_{2}$ structure. This means that the N-A-S-H gel is mostly constructed of a three-dimensional alumino-silciate network, and also contains some two-dimensional branch structures and a small number
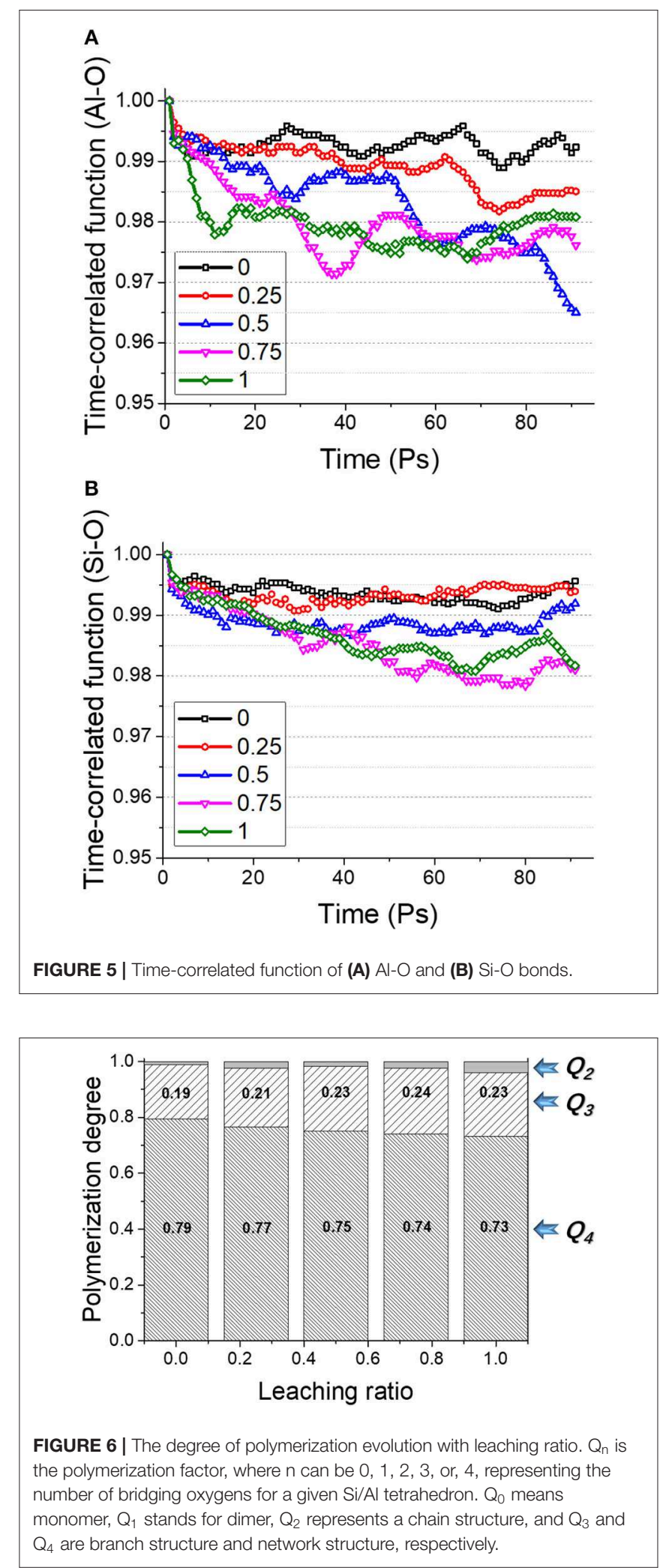

of chain structures. As the leaching ratio increases, the $\mathrm{Q}_{4}$ percentage gradually declines from 79 to $73 \%$, which is replaced by $\mathrm{Q}_{3}$ and $\mathrm{Q}_{2}$ structures, implying that three-dimensional 
network structure is gradually transformed into branch and chain structures. It shows that leaching not only weakens the alumino-silicate skeleton, but also breaks a small amount of the alumino-silicate skeleton.

Under the influence of leaching, the alumino-silicate skeleton of N-A-S-H gel is weakened to some extent, and even fractured, leaching to the decrease in the stability of the overall structure. Herein, the dynamics of the structure is estimated by mean square displacement (MSD), as determined by the following equation. The mobility of the solid species $\mathrm{Si}, \mathrm{Al}$, and $\mathrm{Na}$, of the $\mathrm{N}-\mathrm{A}-\mathrm{S}-\mathrm{H}$ gel is investigated as follows:

$$
\operatorname{MSD}(\mathrm{t})=<\left|r_{i}(t)-r_{i}(0)\right|^{2}>
$$

where $r_{i}(t)$ is the position of atom $i$ at time $t$.

MSD profiles of $\mathrm{Al}, \mathrm{Si}$, and $\mathrm{Na}$ at different leaching ratios are depicted in Figure 7. The MSD profiles increase with fluctuation as relaxation time increases, and this means a slight displacement of the atoms accompanied with vibrations. For the cases without leaching, the MSD of $\mathrm{Si}$ and $\mathrm{Al}$ at 100 ps is just 0.005 and 0.02 $\AA^{2}$, respectively, meaning that the displacement of both types of atoms is $<0.14 \AA$ during 100 ps, which is the typical nature of a solid.

By contrast, the MSD of $\mathrm{Na}$ is around 50 times more than that of $\mathrm{Si}$ and $\mathrm{Al}$, and exhibits a glassy nature like that of physically binding water in cement hydrates (Youssef et al., 2011). Moreover, it has been reported (Zhang et al., 2018a) that the mobility of the sodium depends on its position in the N-A-S$\mathrm{H}$ gel. For ones located at the surface of the N-A-S-H substrate, their mobility is around 100 times more than that of those in the interior. It means surface sodium can be dissociated from the cavities among the alumino-silicate skeleton or exchanged with outside alkali ions, which underlies the dissociation of sodium from the N-A-S-H gel that is called leaching. The sodium species are the most unstable species in the structure.

With the leaching of sodium, the mobility and the amplitude of atomic vibrations increases for both $\mathrm{Al}$ and $\mathrm{Si}$. It indicates a gradual decrease in the stability of the alumino-silicate skeleton of the N-A-S-H gel. Moreover, the increase in the MSD of Al is much more than that of $\mathrm{Si}$, and the value it reaches is around $70 \%$ of that of the easily soluble $\mathrm{Na}$ (reference sample), which is also consistent with the above conclusion that leaching has a direct weakening effect on aluminate species. In previous work, it was demonstrated that the removal of alkalis induces the reduction of $\mathrm{Q}_{4}(\mathrm{Al})$ and $\mathrm{Al}(\mathrm{VI})$ species as observed by 29Si and 27Al MASNMR and FTIR analysis (Longhi et al., 2019). The weakening of the $\mathrm{AlO}_{4}$ tetrahedral structure caused by sodium absence was also characterized by molecular dynamics simulation (Sadat et al., 2016a). Both of these explain the experimental results of the detection of aluminate species in the water soaked geopolymer specimens (Zhang et al., 2016), which means the dealumination of gel and thus dissolution of gel. The dissolution leads to the decrease in geopolymer quality and the coarsening of the pore structure. It also gives an explanation for the Mercury Intrusion Method (MIP) experiments (Yao et al., 2016) which showed an increase in nanopore volume in the geopolymer samples after leaching.
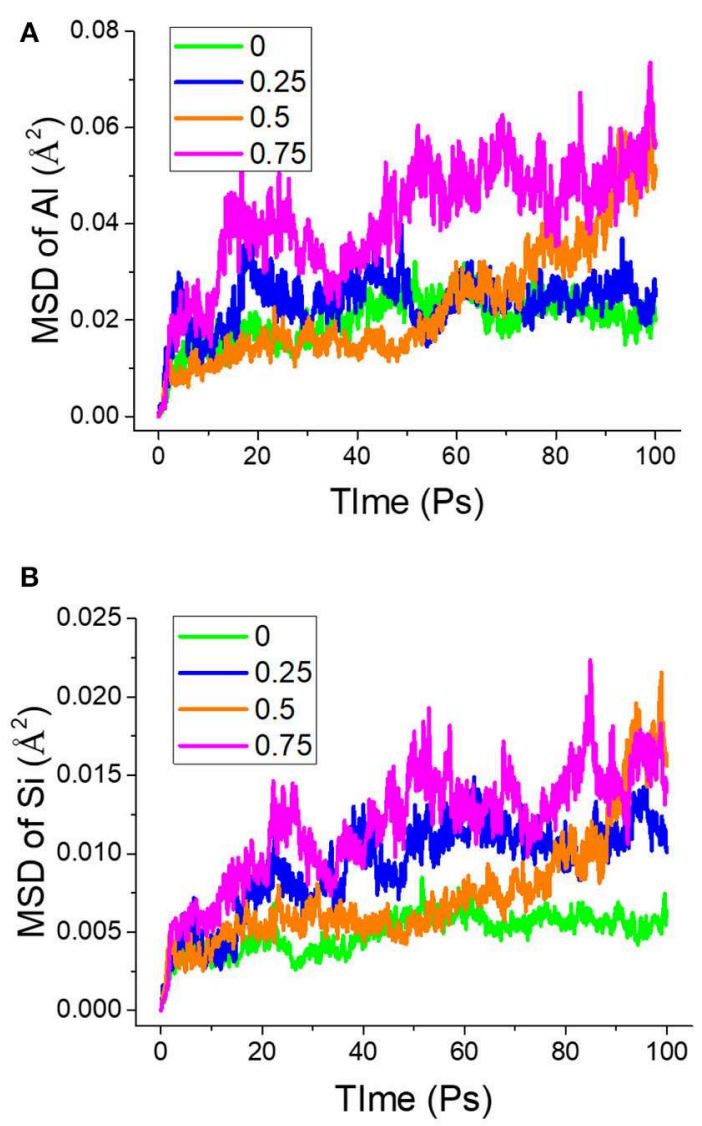

C

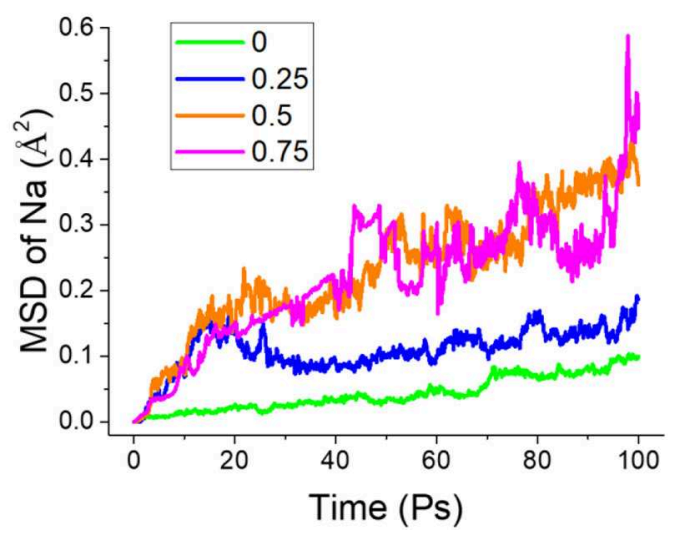

FIGURE 7 | Mean square displacement of (A) Al, (B) Si, and (C) Na under the influence of leaching.

Due to the degradation of the alumino-silicate skeleton, sodium distributed among the skeleton receives less restriction from the skeleton, resulting in the sodium transforming from a glassy state into a flowing state progressively with leaching, as illustrated in Figure 7C. It implies that the rate of sodium dissociating from the N-A-S-H gel is getting faster and faster. Also, it indicates that the dissociation of sodium accelerates the degradation of alumino-silicate skeleton, which in turn promotes 


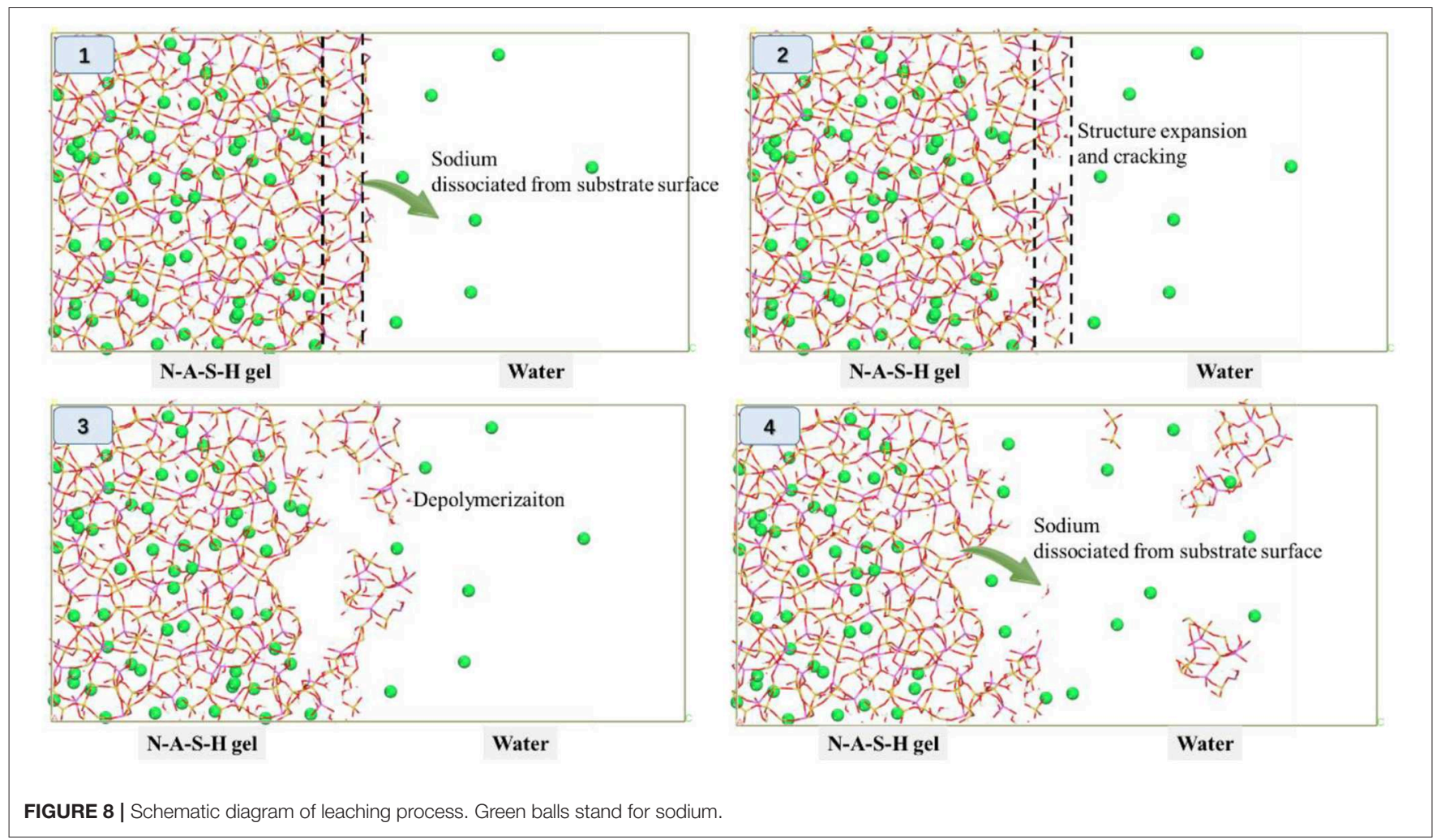

the dissociation of sodium. Therefore, the dissolution of surface sodium is an accelerated process.

According to the above discussion, the mechanism of leaching can be summarized in Figure 8. Loose in the alumino-silicate skeleton, sodium located at the surface of the N-A-S-H substrate is gradually dissociated and diffuses into the bulk water. It results in structure swelling and the weakening of the aluminosilicate skeleton, and then processes into the depolymerization of the skeleton and even the peeling and dissolution of the surface layer of the gel substrate. Subsequently, fresh internal $\mathrm{N}-\mathrm{A}-\mathrm{S}-\mathrm{H}$ gel is exposed, and the sodium in its surface begins to diffuse into the bulk water. A new leaching process starts. In this way, the N-A-S-H gel can be depolymerized layer by layer, resulting in microscopic holes and fissures produced leading to the degradation of the macroscopic properties of the gel.

\section{Mechanical Properties}

Under the influence of leaching, the N-A-S-H gel is weakened and even dissolved. Herein, the mechanical properties of the $\mathrm{N}-\mathrm{A}-\mathrm{S}-\mathrm{H}$ gel before and after leaching is investigated.

Figure 9A shows the stress-strain relations of the N-A-S-H gel during elongation. The curves increase linearly and step into a yield stage at around $60-80 \%$ of the peak value. The peak value decreases with the leaching ratio. Tensile strength and Young's modulus are plotted in Figure 9B, showing a roughly linear relationship with the leaching ratio. Approximately, the tensile strength and Young's modulus decline by respectively 0.45 and $2.55 \mathrm{GPa}$ for every $25 \%$ sodium dissociation. This is caused by the deterioration in terms of the degree of polymerization of the N-A-S-H gel and the strength of Si$\mathrm{O}$ and $\mathrm{Al}-\mathrm{O}$ bonds as discussed in section Alumino-Silicate Skeleton Weakening.

Particularly, the reduction in Young's modulus of the surface gel can result in a mismatch of deformation between the surface and internal gel when it is loaded. Taking the sample with 100\% leaching as an example, the linear deformation of the surface gel is $84.5 \%$ of the internal when they are subject to the same stress. For geopolymer materials with a considerably larger specific surface area, it significantly increases the potential for surface gel peeling.

For the post-peak stage, the curves drop at different rates. The curve for the case of $100 \%$ leaching drops sharply, and the strain at the breaking point is 0.71 . The strain at the breaking point increases with the decrease of the leaching ratio. Figure 9C shows an approximately linear relationship between the leaching ratio and the strain at the breaking point. The strain at the breaking point for the sample with $100 \%$ leaching is around the $37 \%$ of the pristine sample, meaning a significant reduction in ductility of the structure after leaching.

In order to investigate the effect of leaching on the structure evolution during a tensile process, the amount of variation in $\mathrm{Si}-\mathrm{O}-\mathrm{Si}$ and $\mathrm{Al}-\mathrm{O}-\mathrm{Si}$ bonds during elongation is presented in Figure 9D. Before a strain of 0.1, the amount of chemical bonds remains stable, because this is the elastic stage at which the alumino-silicate skeleton can resist tensile strain by deformation only. For the strain between 0.1 and 0.2 , the bond amounts decrease slightly but the variation is almost the same 


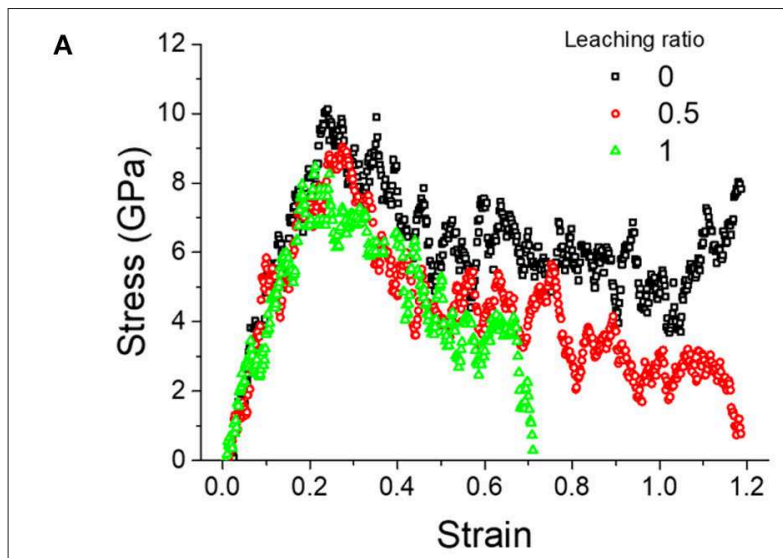

B

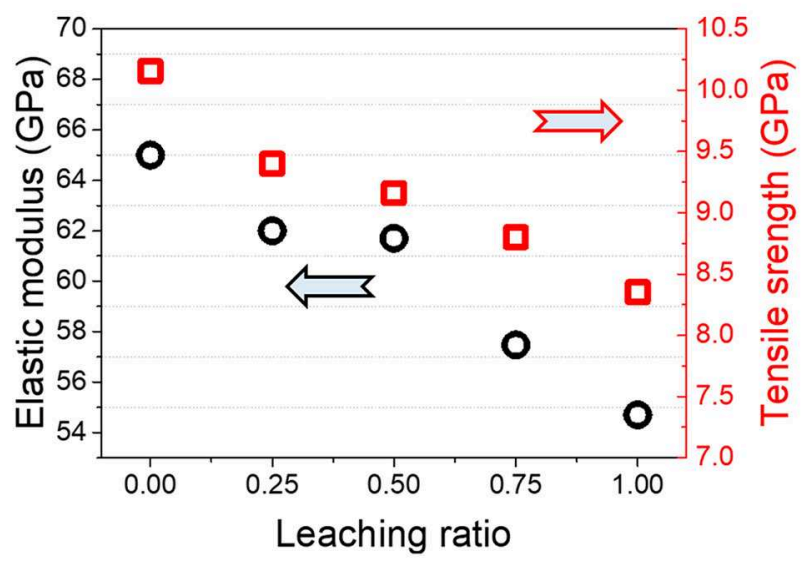

C

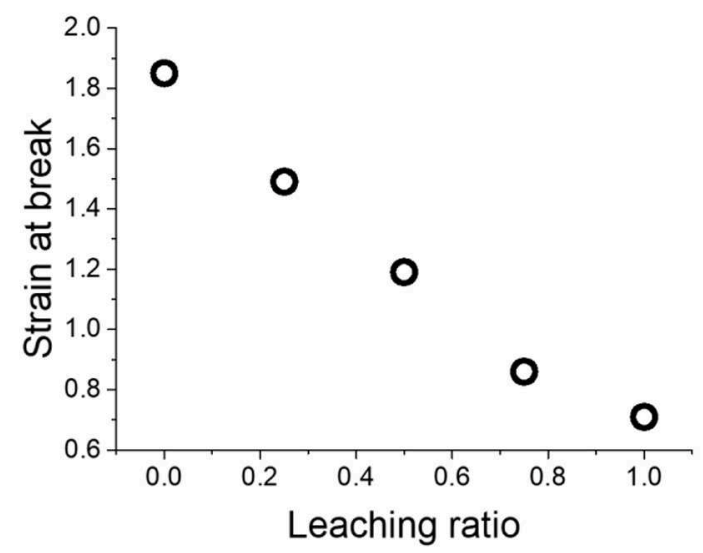

D

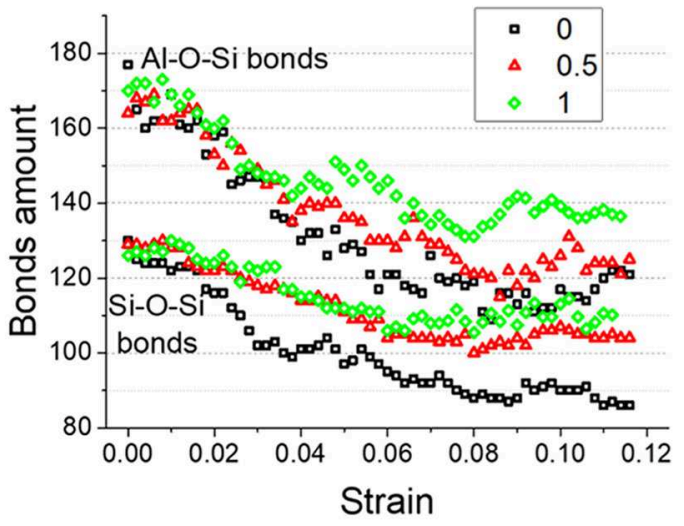

E

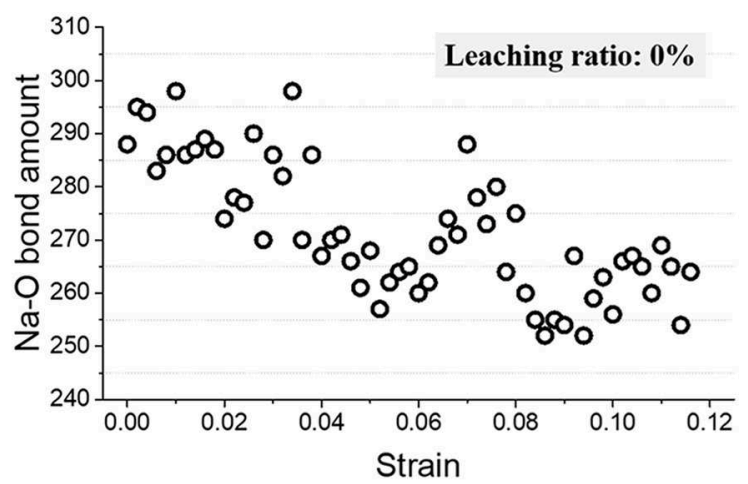

$\mathbf{F}$

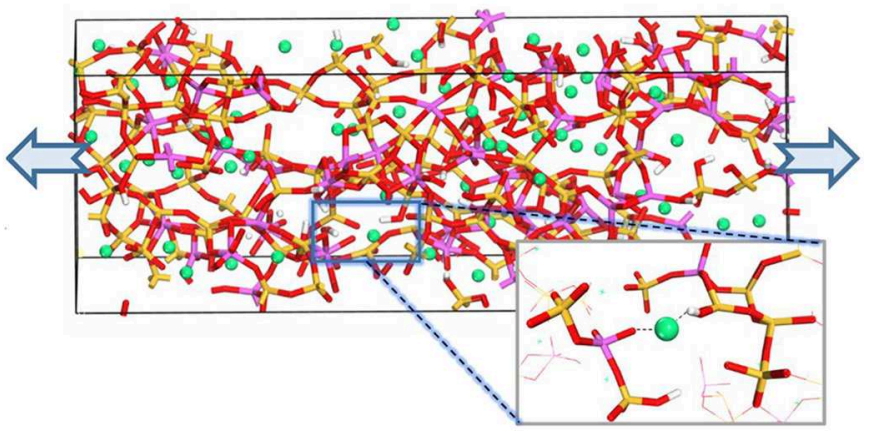

FIGURE 9 | (A) Stress-strain relation of N-A-S-H gels after leaching; (B) tensile strength and elastic modulus, and (C) strain at the breaking point of N-A-S-H; variations of (D) S-O-Si and Si-O-Al bonds and (E) Na-O bond variations as functions of tensile strain; (F) a snapshot of N-A-S-H gel without leaching at a tensile strain of 1.

for all samples. The above discussion is related to the prepeak stage.

In the post-peak stage, as plotted in Figure 9D, the downward gradient of the bond amount increases, implying that the alumosilicate skeleton is broken to consume tensile energy. Meanwhile, the breakage of the skeleton also means the appearance of cracks, leading to a decrease in loading capacity.
Overall, the total amount of broken $\mathrm{Si}-\mathrm{O}-\mathrm{Si}$ and Al-O-Si bonds decreases as the leaching ratio increases, as illustrated in Figure 9D. For the N-A-S-H gel subject to mechanical tests, it elucidates that the lower the amount of leaching, the more energy is consumed.

The bridging effect of sodium underlies divergence of bond breakages between samples with different leaching ratios. 
Figure 9E presents a snapshot of a N-A-S-H gel without leaching at a tensile strain of 1 . Sodium plays roles in connecting the broken alumino-silicate skeleton through the electrostatic force between sodium and oxygen. The sodium distributed among the skeleton effectively transfers tensile stress, contributing to a uniform dispersion of tensile stress.

Moreover, the existence of $\mathrm{Na}-\mathrm{O}$ bonds also increases the integrity of the structure. Figure $9 \mathrm{~F}$ shows the variation of $\mathrm{Na}-\mathrm{O}$ bonds with strain. The downward trend indicates the breakage of $\mathrm{Na}-\mathrm{O}$ bonds under tension. But the broken $\mathrm{Na}-\mathrm{O}$ bonds can be easily reformed by matching with surrounding tetrahedral oxygen. As a result, the breakage and regeneration of $\mathrm{Na}-\mathrm{O}$ bonds occurs simultaneously, resulting in a large fluctuation in the amount of $\mathrm{Na}-\mathrm{O}$ bonds. All of these processes contribute to an improvement of the fracture energy of the N-A-S-H gel.

The above results complement the mechanism of the leaching process shown in Figure 8. The deterioration of mechanical properties only occurs on the N-A-S$\mathrm{H}$ substrate surface that is exposed to solution. When the external environment deteriorates, such as after exposure to temperature variation or external loading, it is more apparent that the dissolution and peeling of the surface layer of N-A-S-H substrate further accelerates sodium dissociation.

\section{CONCLUSIONS}

This paper simulated the leaching of a surface of a N-A-S-H gel with a volume of $2 \times 2 \times 2 \mathrm{~nm}$ to reveal the mechanism of alkali dissolution from the gels of geopolymers at the nanoscale.

1. Sodium plays roles in balancing the charges of $\left[\mathrm{AlO}_{4}\right]$ tetrahedrons, and its absence leads to local structures showing a negative charge, resulting in locally mutual repulsion between tetrahedrons, and eventually swelling the overall structure. Leaching may not affect silicate species directly.

2. Sodium absence makes the originally stable non-bridging oxygen active again, promoting hydrolytic reactions. Newly

\section{REFERENCES}

Arbi, K., Nedeljković, M., Zuo, Y., and Ye, G. (2016). A review on the durability of alkali-activated fly ash/slag systems: advances, lssues, and perspectives. Ind. Eng. Chem. Res. 55:5439-5453. doi: 10.1021/acs.iecr.6b00559

Bai, C., Liu, L., and Sun, H. (2012). Molecular dynamics simulations of methanol to olefin reactions in HZSM-5 zeolite using a reaxff force field. J. Phys. Chem. 116, 7029-7039. doi: 10.1021/jp300221j

Bernal, S. A., Provis, J. L., Walkley, B., Nicolas, R. S., Gehman, J. D., Brice, D. G., et al. (2013). Gel nanostructure in alkali-activated binders based on slag and fly ash, and effects of accelerated carbonation. Cem. Concr. Res. 53, 127-144. doi: 10.1016/j.cemconres.2013.06.007

Bonnaud, P. A., Ji, Q., Coasne, B., Pellenq, R. J., and Van Vliet, K. J. (2012). Thermodynamics of water confined in porous calcium-silicate-hydrates. Langmuir 28, 11422-11432. doi: 10.1021/la301738p

Bortnovsky, O., Dědeček, J., TvaruŽková, Z., Sobalík, Z., and Šubrt, J. (2008). Metal ions as probes for characterization of geopolymer materials. J. Am. Ceram. Soc. 91, 3052-3057. doi: 10.1111/j.1551-2916.2008.02577.x produced hydroxyls exacerbate non-conservation of charge of the N-A-S-H system, further swelling the structure.

3. Under the influence of leaching, the alumino-silicate skeleton of the N-A-S-H gel is weakened to some extent, and even fractured, leading to a decrease in the stability of the overall structure, which in turn promotes the dissociation of sodium.

4. The structure deterioration mentioned above leads to the degradation of mechanical properties of surface gel, including strength, Young's modulus, and ductility, which promotes the disaggregation of the surface gel. Sodium plays roles in connecting the skeleton by the electrostatic force with tetrahedral oxygen, which transfers stress and contributes to uniform stress dispersion.

5. Leaching starts from the gel surface, in which the gel swells and is weakened in the above manner, resulting in depolymerization and peeling. Then, a fresh internal N-A-S$\mathrm{H}$ gel surface is exposed and a new leaching process begins. In this way, the gel peels off layer by layer, resulting in microscopic holes and fissures.

\section{DATA AVAILABILITY STATEMENT}

The raw data supporting the conclusions of this article will be made available by the authors, without undue reservation, to any qualified researcher.

\section{AUTHOR CONTRIBUTIONS}

HW: writing-original draft preparation. LY: supervision. YZ: conceptualization, methodology, software, visualization, and investigation.

\section{FUNDING}

This research was financially supported by the National Natural Science Foundation of China (51578143) and the National Key Research and Development Program of China (2018YFC0705400).

Duxson, P., Fernández-Jiménez, A., Provis, J. L., Lukey, G. C., Palomo, A., and Deventer, J. S. J. V. (2007). Geopolymer technology: the current state of the art. J. Mater. Sci. 42, 2917-2933. doi: 10.1007/s10853-0060637-z

Duxson, P., Lukey, G., Separovic, F., and Van Deventer, J. (2005). Effect of alkali cations on aluminum incorporation in geopolymeric gels. Ind. Eng. Chem. Res. 44, 832-839. doi: 10.1021/ie0494216

Duxson, P., Provis, J., Lukey, G., Van Deventer, J., Separovic, F., and Gan, Z. (2006). 39K NMR of free potassium in geopolymers. Ind. Eng. Chem. Res. 45, 9208-9210. doi: 10.1021/ie060838g

Habert, G., Lacaillerie, J. B. D. E. D., and Roussel, N. (2011). An environmental evaluation of geopolymer based concrete production: reviewing current research trends. J. Clean. Prod. 19, 1229-1238. doi: 10.1016/j.jclepro.2011.03.012

Hoover, W. G. (1985). Canonical dynamics: equilibrium phase-space distributions. Phys. Rev. A Gen. Phys. 31, 1695-1697. doi: 10.1103/PhysRevA.31.1695

Hoover, W. G. (1986). Constant-pressure equations of motion. Phys. Rev. A Gen. Phys. 34, 2499-2500. doi: 10.1103/PhysRevA.34.2499 
Hou, D., Li, T., and Wang, P. (2018a). Molecular dynamics study on the structure and dynamics of $\mathrm{NaCl}$ solution transport in the nanometer channel of CASH gel. ACS Sustain. Chem. Eng. 6, 9498-9509. doi: 10.1021/acssuschemeng.8b02126

Hou, D., and Li, Z. (2014). Molecular dynamics study of water and ions transport in nano-pore of layered structure: a case study of tobermorite. Microporous Mesoporous Mater. 195, 9-20. doi: 10.1016/j.micromeso.2014.04.011

Hou, D., Ma, H., Li, Z., and Jin, Z. (2014). Molecular simulation of "hydrolytic weakening": a case study on silica. Acta Mater. 80, 264-277. doi: 10.1016/j.actamat.2014.07.059

Hou, D., Yu, J., and Wang, P. (2019). Molecular dynamics modeling of the structure, dynamics, energetics and mechanical properties of cement-polymer nanocomposite. Compos. B Eng. 162, 433-444. doi: 10.1016/j.compositesb.2018.12.142

Hou, D., Zhang, J., Pan, W., Zhang, Y., and Zhang, Z. (2020). Nanoscale mechanism of ions immobilized by the geopolymer: a molecular dynamics study. J. Nucl. Mater. 528:151841. doi: 10.1016/j.jnucmat.2019.151841

Hou, D., Zhang, Y., Yang, T., Zhang, J., Pei, H., Zhang, J., et al. (2018b). Molecular structure, dynamics, and mechanical behavior of sodium aluminosilicate hydrate (NASH) gel at elevated temperature: a molecular dynamics study. Phys. Chem. Chem. Phys. 20, 20695-20711. doi: 10.1039/C8CP03411G

Kani, E. N., Allahverdi, A., and Provis, J. L. (2012). Efflorescence control in geopolymer binders based on natural pozzolan. Cem. Concr. Compos. 34, 25-33. doi: 10.1016/j.cemconcomp.2011.07.007

Lloyd, R. R., Provis, J. L., and Van Deventer, J. S. (2010). Pore solution composition and alkali diffusion in inorganic polymer cement. Cem. Concr. Res. 40, 1386-1392. doi: 10.1016/j.cemconres.2010.04.008

Longhi, M. A., Rodríguez, E. D., Walkley, B., Zhang, Z., and Kirchheim, A. P. (2020). Metakaolin-based geopolymers: relation between formulation, physicochemical properties and efflorescence formation. Compos. B Eng. 182:107671. doi: 10.1016/j.compositesb.2019.107671

Longhi, M. A., Walkley, B., Rodríguez, E. D., Kirchheim, A. P., Zhang, Z., and Wang, H. (2019). New selective dissolution process to quantify reaction extent and product stability in metakaolin-based geopolymers. Compos. B Eng. 176:107172. doi: 10.1016/j.compositesb.2019.107172

Lu, L., Zhang, Y., and Yin, B. (2020). Structure evolution of the interface between graphene oxide-reinforced calcium silicate hydrate gel particles exposed to high temperature. Comput. Mater. Sci. 173:109440. doi: 10.1016/j.commatsci.2019.109440

Provis, J., and Van Deventer, J. (2007). Geopolymerisation kinetics. 2. reaction kinetic modelling. Chem. Eng. Sci. 62, 2318-2329. doi: 10.1016/j.ces.2007.01.028

Provis, J. L., Palomo, A., and Shi, C. (2015). Advances in understanding alkali-activated materials. Cem. Concr. Res. 78, 110-125. doi: 10.1016/j.cemconres.2015.04.013

Sadat, M. R., Bringuier, S., Asaduzzaman, A., Muralidharan, K., and Zhang, L. (2016a). A molecular dynamics study of the role of molecular water on the structure and mechanics of amorphous geopolymer binders. J. Chem. Phys. 145, 1633-1503. doi: 10.1063/1.49 64301

Sadat, M. R., Bringuier, S., Muralidharan, K., Runge, K., Asaduzzaman, A., and Zhang, L. (2016b). An atomistic characterization of the interplay between composition, structure and mechanical properties of amorphous geopolymer binders. J. Noncryst. Solids 434, 53-61. doi: 10.1016/j.jnoncrysol.2015. 11.022

Shi, C., Jiménez, A. F., and Palomo, A. (2011). New cements for the 21st century: the pursuit of an alternative to Portland cement. Cem. Concr. Res. 41, 750-763. doi: 10.1016/j.cemconres.2011.03.016

Singh, B., Ishwarya, G., Gupta, M., and Bhattacharyya, S. (2015). Geopolymer concrete: a review of some recent developments. Constr. Build. Mater. 85, 78-90. doi: 10.1016/j.conbuildmat.2015.03.036

Singh, P. S., Trigg, M., Burgar, I., and Bastow, T. (2005). Geopolymer formation processes at room temperature studied by $29 \mathrm{Si}$ and $27 \mathrm{Al}$ MAS-NMR. J. Mater. Sci. Eng. A 396, 392-402. doi: 10.1016/j.msea.200 5.02 .002

Škvára, F., Pavlasová, S., Kopecký, L., Myšková, L., and Alberovská, L. (2008). "High temperature properties of fly ash-based geopolymers," in
Proceedings of the 3rd International Symposium on Non-Traditional Cement and Concrete, 741-750.

Škvára, F., Šmilauer, V., Hlaváček, P., Kopecký, L., and Cilova, Z. (2012). A weak alkali bond in $(\mathrm{N}, \mathrm{K})-\mathrm{A}-\mathrm{S}-\mathrm{H}$ gels: evidence from leaching and modeling. Ceram. Silik. 56, 374-382.

Szklorzová, H., and Bílek, V. (2008). "Influence of alkali ions in the activator on the performance of alkali-activated mortars,"in Proceedings of the $3 \mathrm{rd}$ International Symposium on Non-traditional Cement and Concrete (Brno, Czech Republic), 10-12.

Wan, X., Hou, D., Zhao, T., and Wang, L. (2017). Insights on molecular structure and micro-properties of alkali-activated slag materials: a reactive molecular dynamics study. Constr. Build. Mater. 139, 430-437. doi: 10.1016/j.conbuildmat.2017.02.049

Yao, X., Yang, T., and Zhang, Z. (2016). Compressive strength development and shrinkage of alkali-activated fly ash-slag blends associated with efflorescence. Mater. Struc. 49, 2907-2918. doi: 10.1617/s11527-015-0694-3

Youssef, M., Pellenq, R. J. M., and Yildiz, B. (2011). Glassy nature of water in an ultraconfining disordered material: the case of calcium-silicate-hydrate. J. Am. Chem. Soc. 133, 2499-2510. doi: 10.1021/ja107003a

Zhang, M., Zhao, M., Zhang, G., Mann, D., Lumsden, K., and Tao, M. (2016). Durability of red mud-fly ash based geopolymer and leaching behavior of heavy metals in sulfuric acid solutions and deionized water. Constr. Build. Mater. 124, 373-382. doi: 10.1016/j.conbuildmat.2016.07.108

Zhang, Y., Li, T., Hou, D., Zhang, J., and Jiang, J. (2018a). Insights on magnesium and sulfate ions' adsorption on the surface of sodium alumino-silicate hydrate (NASH) gel: a molecular dynamics study. Phys. Chem. Chem. Phys. 20:18297. doi: 10.1039/C8CP02469C

Zhang, Y., Wan, X., Hou, D., Zhao, T., and Cui, Y. (2018d). The effect of mechanical load on transport property and pore structure of alkali-activated slag concrete. Constr. Build. Mater. 189, 397-408. doi: 10.1016/j.conbuildmat.2018.09.009

Zhang, Y., Yang, T., Jia, Y., Hou, D., Li, H., Jiang, J., et al. (2018c). Molecular dynamics study on the weakening effect of moisture content on graphene oxide reinforced cement composite. Chem. Phys. Lett. 708, 177-182. doi: 10.1016/j.cplett.2018.08.023

Zhang, Y., Zhang, J., Jiang, J., Hou, D., and Zhang, J. (2018b). The effect of water molecules on the structure, dynamics, and mechanical properties of sodium aluminosilicate hydrate (NASH) gel: a molecular dynamics study. Const. Build. Mater. 193, 491-500. doi: 10.1016/j.conbuildmat.2018. 10.221

Zhang, Y., Zhang, Q., Hou, D., and Zhang, J. (2020). Tuning interfacial structure and mechanical properties of graphene oxide sheets/polymer nanocomposites by controlling functional groups of polymer. Appl. Surf. Sci. 504:144152. doi: 10.1016/j.apsusc.2019.144152

Zhang, Z., Provis, J. L., Ma, X., Reid, A., and Wang, H. (2018). Efflorescence and subflorescence induced microstructural and mechanical evolution in fly ash-based geopolymers. Cem. Concr. Compos. 92, 165-177. doi: 10.1016/j.cemconcomp.2018.06.010

Zhang, Z., Provis, J. L., Reid, A., and Wang, H. (2014). Fly ash-based geopolymers: the relationship between composition, pore structure and efflorescence. Cem. Concr. Res. 64, 30-41. doi: 10.1016/j.cemconres.2014. 06.004

Zhang, Z., Wang, H., Provis, J. L., and Reid, A. (2013). "Efflorescence: a critical challenge for geopolymer applications?" in Concrete Institute of Australia's Biennial National Conference (Gold Coast, QLD), 1-10. Available online at: http://www.ceramics-silikaty.cz/index.php?page $=$ cs_detail_doi\&id $=250$

Conflict of Interest: The authors declare that the research was conducted in the absence of any commercial or financial relationships that could be construed as a potential conflict of interest.

Copyright $\odot 2020$ Wan, Yuan and Zhang. This is an open-access article distributed under the terms of the Creative Commons Attribution License (CC BY). The use, distribution or reproduction in other forums is permitted, provided the original author(s) and the copyright owner(s) are credited and that the original publication in this journal is cited, in accordance with accepted academic practice. No use, distribution or reproduction is permitted which does not comply with these terms. 